\title{
A logistic regression analysis of risk factors in ME/CFS pathogenesis
}

\author{
Eliana M. Lacerda ${ }^{1 *}$ (D) Keith Geraghty ${ }^{2}$, Caroline C. Kingdon ${ }^{1}$, Luigi Palla ${ }^{1}$ and Luis Nacul ${ }^{1}$
}

\begin{abstract}
Background: Myalgic Encephalomyelitis/Chronic Fatigue Syndrome (ME/CFS) is a complex disease, whose exact cause remains unclear. A wide range of risk factors has been proposed that helps understanding potential disease pathogenesis. However, there is little consistency for many risk factor associations, thus we undertook an exploratory study of risk factors using data from the UK ME/CFS Biobank participants. We report on risk factor associations in ME/CFS compared with multiple sclerosis participants and healthy controls.

Methods: This was a cross-sectional study of 269 people with ME/CFS, including 214 with mild/moderate and 55 with severe symptoms, 74 people with multiple sclerosis (MS), and 134 healthy controls, who were recruited from primary and secondary health services. Data were collected from participants using a standardised written questionnaire. Data analyses consisted of univariate and multivariable regression analysis (by levels of proximity to disease onset).
\end{abstract}

Results: A history of frequent colds $(\mathrm{OR}=8.26, P<=0.001)$ and infections $(\mathrm{OR}=25.5, P=0.015)$ before onset were the strongest factors associated with a higher risk of ME/CFS compared to healthy controls. Being single (OR $=4.41$, $P<=0.001)$, having lower income $(\mathrm{OR}=3.71, P<=0.001)$, and a family history of anxiety is associated with a higher risk of ME/CFS compared to healthy controls only $(\mathrm{OR}=3.77, \mathrm{P}<0.001)$. History of frequent colds $(\mathrm{OR}=6.31, P<$ $0.001)$ and infections before disease onset $(\mathrm{OR}=5.12, P=0.005)$, being single $(\mathrm{OR}=3.66, P=0.003)$ and having lower income $(\mathrm{OR}=3.48, P=0.001)$, are associated with a higher risk of ME/CFS than MS. Severe ME/CFS cases were associated with lower age of ME/CFS onset $(\mathrm{OR}=0.63, P=0.022)$ and a family history of neurological illness $(\mathrm{OR}=6.1, P=0.001)$.

Conclusions: Notable differences in risk profiles were found between ME/CFS and healthy controls, ME/CFS and MS, and mild-moderate and severe ME/CFS. However, we found some commensurate overlap in risk associations between all cohorts. The most notable difference between ME/CFS and MS in our study is a history of recent infection prior to disease onset. Even recognising that our results are limited by the choice of factors we selected to investigate, our findings are consistent with the increasing body of evidence that has been published about the potential role of infections in the pathogenesis of ME/CFS, including common colds/flu.

Keywords: Myalgic encephalomyelitis/chronic fatigue syndrome, Multiple sclerosis, Risk factors, Illness severity

\section{Background}

Myalgic Encephalomyelitis (ME) was originally described as a post-infectious disease causing malaise, muscle weakness, and nervous system complaints, primarily pain, cognitive dysfunction, and sleep disturbance [1]. Chronic fatigue syndrome (CFS) is an alternative label introduced in the late 1980 s to describe a pattern of

\footnotetext{
* Correspondence: Eliana.lacerda@lshtm.ac.uk

${ }^{1}$ Faculty of Infectious and Tropical Diseases, London School of Hygiene \&

Tropical Medicine, London WC1E 7HT, UK

Full list of author information is available at the end of the article
}

symptoms, specifically unexplained fatigue [2]. The two names are often used synonymously. ME/CFS prevalence rates vary widely across studies, but a rate between 0.2 and $0.5 \%$ is commonly reported for adults [3]. A number of different diagnostic criteria are used to identify potential cases. In the UK, the National Institute for Health and Care Excellence (NICE) has recommended a diagnosis after 6 months of persistent unexplained fatigue, not relieved by rest, which results in a substantial loss of normal physical or social function [4]. The US Centre

(c) The Author(s). 2019 Open Access This article is distributed under the terms of the Creative Commons Attribution 4.0 International License (http://creativecommons.org/licenses/by/4.0/), which permits unrestricted use, distribution, and 
for Disease Control (CDC) criteria from 1994 require a wider set of characteristic symptoms [5], whilst other criteria require the presence of post-exertional malaise [6]. The aetiology and pathogenesis of ME/CFS remains contested but many patients recount their symptoms starting after an infection and an increasing number of studies find neuro-immunological and cellular abnormalities that support an association between infection and proinflammatory immune alterations in ME/CFS [7, 8].

A range of disparate risk factors has been proposed as disease-specific. A number of studies suggest a higher prevalence of ME/CFS among family members, particularly twins [9], suggesting a genetic heritability risk factor. Underhill and O'Gorman found that $20.5 \%$ of members of a US CFS sample, reported a family member with CFS (18\% being blood relatives), suggesting a strong genetic predisposition [10]. A genetic study has found a number of DNA single-nucleotide polymorphisms (SNPs) from over 906,600 known SNPs analysed from ME/CFS subjects, and identified 442 potential loci that might be associated with ME/CFS [11]. Despite the small sample size, this study exemplifies the vast complexity of genes as a risk factor in ME/CFS. The relative-risk attached to such factors is difficult to ascertain from a review of the literature. A systematic scoping review by Hempel et al. analysed risk factors for ME/CFS using multiple predictors [12], but from 10,768 relevant publications, only 11 met inclusion criteria. Hempel et al. concluded that there was poor replication of risk factors across multiple studies, so that few demographic, medical, psychological, social and environmental factors can be considered suitable predictive indicators in clinical practice. A major problem in the studies reviewed is the variability of diagnostic criteria used (including in self-reported ME/CFS) and a lack of consistent methodology. The most credible risk factors for ME/CFS onset are sex, with a higher female to male ratio [13] and a history of infection [14], the latter highlighting the importance of environmental factors in the aetiology of ME/CFS, which may act independently or interact with genetic risk factors. Large population datasets have been used to explore pre-morbid health factors and ME/CFS. There is some evidence of a link between affective disorders (anxiety and depression) and ME/CFS while work on pre-morbid activity levels has not been able to establish a firm link with prior levels of physical activity. A link between CFS and childhood abuse has been suggested, although results from case-control studies have been contradictory $[15,16]$.

The need to further explore and assess risk factors for ME/CFS prompted this study, which investigates potential risk factors by comparing data from a cohort of the UK ME/CFS Biobank (UKMEB) participants. This cohort includes people with ME/CFS, people with multiple sclerosis (MS), and healthy controls.

\section{Methods}

The UKMEB team has collected patient data and biological samples from informed consenting participants since 2012. Recruitment procedures for the UKMEB have been exemplified elsewhere, in a publication that also lists the data collection instruments used [17]. Recruitment for the UKMEB cohort included the invitation of potential participants by collaborating NHS Services (primary and secondary care), who used their databases to identify people diagnosed with ME/CFS, people diagnosed with MS, and potential healthy controls, aged between 18 and 60 years. The NHS Services sent out invitation packs provided by the research team containing an invitation letter from the health service with information about the study (with specific information sheets for cases and controls), a consent form, a questionnaire to assess symptoms, and a refusal form. People with ME/CFS who are bed- or home-bound are often unable to attend the NHS services, and were invited by support groups. Health services and higher education institutions such as the LSHTM, also handed invitation packs for potential healthy controls.

Once signed consent forms and questionnaires had been assessed by the research team, those who had a likely diagnosis of ME/CFS according to the research criteria (CDC-1994 [5] or Canadian Consensus Criteria [6]) and who were able to travel were invited to a recruiting centre by the research team, while those with severe disease and mobility restrictions were visited at home by a clinical researcher. Participants were excluded if they had: i) used drugs known to alter immune function (e.g. azathioprine, cyclosporine, methotrexate, steroids), anti-viral medications and vaccinations in the 3 months prior to recruitment; or ii) a history of acute or chronic infectious diseases such as hepatitis B and C, tuberculosis, HIV (but not herpes virus or other retrovirus infection); iii) a history of other severe illness (such as cancer, coronary heart disease, or uncontrolled diabetes), and/or and severe mood disorders, iv) a history of illicit drug use; and/or v) a BMI $\geq 40$. Pregnant women and those within 12 months post-partum and/or currently lactating were also excluded. Those people who had offered to take part but were ineligible were thanked by the research manager and a full explanation of the reason was given.

At the clinical appointment, all participants were examined by a health professional; the diagnosis of ME/ CFS for research purposes was reached only after this assessment and following the results of the clinical blood tests taken, which were aimed to exclude other conditions that could explain chronic fatigue. All participants with MS had a prior diagnosis from a UK NHS neurology consultant according to NHS guidelines [18]. 
We invited 2430 individuals identified by our collaborating NHS services (942 with ME/CFS, 278 with MS and 1210 healthy), in addition to 112 people with a confirmed medical diagnosis of ME/CFS invited by ME/CFS support groups, of whom 84 invited healthy individuals to act as controls. Of the total potential participants invited, 138 declined to participate ( $45 \mathrm{had}$ a possible diagnosis of ME/ CFS, 26 MS, 48 healthy controls; 19 received refusal forms were incomplete) and 1828 were non-respondents. The distribution by sex and age group of those who declined to participate in all groups, was similar to the groups of those recruited, and the proportion of stated refusals was similar across the recruiting health services varying between 4 and 10\% (median 6.3\%, IQR 5.3 to $8.9 \%$ ). From the consenting potential participants, 660 were assessed for eligibility as previously described, of which 532 were recruited. After additional exclusions, per study protocol, the final cohort considered in this paper includes ME/CFS participants with mild/moderate (n$214)$, and with severe symptoms $(n-55)$, participants with MS (n-74), and healthy controls $(n-134)$.

\section{Data analysis}

UKMEB participant questionnaire responses [17] were grouped under the following headings: socio-economic, demographic, family health history, lifestyle, co-morbidities, and other potential risk factors associated with ME/CFS (See Additional file 1). All these were self-reported, as we did not have access to their medical records to further explore the presence of these risk factors. Due to the cross sectional design of the study, with control groups (where controls are either healthy or MS subjects), logistic regression was used for prediction (binary outcome, logit link, structural linear model, with model parameters estimated by maximum likelihood). Because of the limited sample size I number of cases and the presence of a large number of predictors within a logistic regression prediction model, the framework used for analysis considered separate variable domains for prediction of the outcome (ME/CFS cases) versus one of the two comparison groups (i.e. people with MS, and healthy controls), in order to select the predictors. The analysis framework was inspired by a conceptual approach to risk factor modelling according to which risk factors can be separated into distinct hierarchical levels relative to the outcome [18].

After running univariate logistic regression analyses for each putative risk factor in all domains (Table 1), we included in the multivariable logistic regression models those factors that showed a statistically significant difference with the comparison group $(P \leq 0.10)$. The following variables from the recent exposures domain 'immunisations' and 'BCG vaccination' were later aggregated as one variable named 'immunisation(s) before onset'; likewise, 'meningitis' and 'other serious infection', were aggregated
Table 1 List of variables used in the univariate logistic regression analyses with all comparison groups, organised by domains

\begin{tabular}{|c|c|}
\hline Domains & List of variables \\
\hline Demographic & $\begin{array}{l}\text { Age at survey (or age at disease } \\
\text { onset for the diseased groups), } \\
\text { sex, ethnicity. }\end{array}$ \\
\hline Socio-economic & $\begin{array}{l}\text { Marital status, education, } \\
\text { individual income, index of } \\
\text { multiple deprivation }{ }^{a} \text {. }\end{array}$ \\
\hline Family health history & $\begin{array}{l}\text { High blood pressure, diabetes, } \\
\text { heart problems, asthma, allergies, } \\
\text { depression, anxiety, mental health } \\
\text { problems, learning disabilities, } \\
\text { physical disabilities, cancer, ME/CFS, } \\
\text { MS, other neurological problems, } \\
\text { tuberculosis, any other health } \\
\text { problems. }\end{array}$ \\
\hline Lifestyle & $\begin{array}{l}\text { Smoking status, alcohol } \\
\text { consumption/week, physical } \\
\text { activity }\end{array}$ \\
\hline $\begin{array}{l}\text { Previous morbidity } \\
\text { (prior to disease onset) }\end{array}$ & $\begin{array}{l}\text { High blood pressure, heart } \\
\text { problems, asthma, allergies, } \\
\text { depression, anxiety, high levels } \\
\text { of stress, history of frequent } \\
\text { coughs/colds, intolerance to } \\
\text { alcoholic drinks, intolerance to } \\
\text { sugar, other health problems. }\end{array}$ \\
\hline $\begin{array}{l}\text { Recent exposures ( } 6 \text { months } \\
\text { prior to disease onset) }\end{array}$ & $\begin{array}{l}\text { Lived on a farm, tick bites, } \\
\text { vaccines/immunisations, } \\
\text { travelling overseas, flooding, } \\
\text { radiation, carbon monoxide (CO), } \\
\text { pesticides, any other chemicals, } \\
\text { had meningitis, had any other } \\
\text { serious infection, had any head } \\
\text { injury, had a major operation, } \\
\text { contraceptive pill (women only), } \\
\text { lived in a house with gas or oil } \\
\text { appliances (for heating or cooking), } \\
\text { lived in a house with a gas fire, } \\
\text { BCG vaccination. }\end{array}$ \\
\hline
\end{tabular}

ME/CFS Myalgic Encephalomyelitis/Chronic Fatigue Syndrome, MS Multiple Sclerosis.

${ }^{a}$ Index of multiple deprivation refers to area of residence [19]. All other variables are as reported by research participants

into a new variable named 'infection(s) before onset'. Subsequently, we ran the multivariable models, starting with the more distal domain (demographic) and working towards the proximate domain (recent exposures) to the outcome. The model selection strategy was to add all the variables of the subsequent domain and, in a step-wise manner, remove those whose likelihood ratio test (comparing reduced and full model) had $P$-value $>0.05$. The overall model fit (Pearson chi squared test, pseudo $\mathrm{R}$ squared) and predictive ability (sensitivity/specificity, correct classification rate) were also assessed for all models. The analyses were conducted with complete cases. The analyses were performed with Stata 15.1 [20].

\section{Results}

We found a 3:1 female to male ratio in our ME/CFS and MS participant groups; however, the female/male ratio 
in the healthy control group was $1.5: 1(P=0.011)$. The age group distribution was similar among the healthy and ME/CFS groups $(P=0.943)$; the MS group had a higher proportion of individuals over 30 years of age $(P=0.002)$. The most common ethnicity reported by participants in all groups was white British (>90\%), with the groups of ME/CFS with severe symptoms and of healthy controls reporting a slightly more diverse ethnic background which still amounted to a small proportion of participants $(<10 \%)$.

In Table 2 we present a description of participants from the UK ME/CFS Biobank, by category of recruitment and each distinct domain, containing distinct sets of variables.

Table 3 shows the variables associated with the outcome in each domain level $(P<0.10)$, with comparisons between ME/CFS cases and healthy controls, and ME/ CFS and MS cases.

From the multivariable logistic regression analysis for each of the comparisons, we found that compared to healthy controls, participants with ME/CFS were less likely to be in a relationship (be single), more likely to have a lower income, to report a family history (but not a personal history) of anxiety, and to report frequent colds and coughs, and infections in the 6 months prior to disease onset (Table 4). The model fit statistics resulted in Pearson chi-square $P=0.80$ and pseudo $\mathrm{R}$ squared $=0.33,78 \%$ of individuals correctly classified, sensitivity of $83 \%$ and specificity of $71 \%$. Similarly, by comparing ME/CFS and MS participants, we found increased risks of ME/CFS related to not being in a relationship, have a lower income, have a history of predisposition to colds and coughs, and to having an infectious disease in the 6 months before disease onset (Table 5). This model had worse model fit statistics with Pearson chi-square $P=0.004$ and pseudo $\mathrm{R}$ squared $=$ $0.26,82 \%$ of individuals correctly classified, sensitivity of $95 \%$ and specificity of $34 \%$.

Those with severe ME/CFS were more likely to be younger; 15 of these participants reported a family history of neurological problems, of which the most commonly reported were stroke (4) and Parkinson's disease (3/15); 9/15 reported that their father was affected and $4 / 15$, their mother. Of the 9 people with mild-moderate ME/CFS who reported neurological family problems, 4 of those reported had a family history of dementia, 5 reported that it was their mother who was affected.

\section{Discussion}

Our recruited UKMEB cohort reflects the predominance of ME/CFS and MS in females that has been reported in the literature. There is consistent evidence for a higher rate of ME/CFS among girls and women [21], with rates among girls increasing above those of boys post-puberty [22]. A
Spanish study of disease epidemiology among 1309 CFS patients meeting the Fukuda criteria found a $90 \%$ female dominance [23], however ratios between 2:1 to 4:1 are often reported [3]. This female dominance is not uncommon in autoimmune diseases; MS affects more women than men in a similar ratio [24]. In terms of epidemiological and neuro-immune characteristics, associations have been drawn between ME/CFS and MS, fibromyalgia, and rheumatoid arthritis [25]. However, we also must consider that the majority of our cohort was recruited from primary/ secondary care services, which have been reported to have higher attendance of females, particularly between 16 and 60 years of age, when the gender gap was observed in the UK [26], The gender differences for health care seeking varies greatly across populations [26, 27], and we must take these variations into account when interpreting study results that recruit from health services.

\section{$\mathrm{ME} / \mathrm{CFS}$ v healthy controls}

Most participants with ME/CFS anecdotally report their illness started after an infection [28] and our study affirms the importance of infection as a strong risk factor for $\mathrm{ME} /$ CFS onset. Our findings indicate that a history of frequent colds and infection in the 6 months preceding disease onset is associated with a higher risk of ME/CFS, compared with healthy controls and participants with MS. Research has shown that ME/CFS is linked with exposure to EpsteinBarr virus, Coxsackie B, Human Herpes virus 6 and 7, and Coxiella burnetii $[14,29,30]$, with stronger associations with infections in those with more severe acute response to infections [31]. Chia and Chia proposed a link between ME/CFS and enterovirus infection after the biopsies from 135/165 CFS patients (82\%) stained positive for VP1 within parietal cells, versus just $7 / 34(20 \%)$ of healthy controls [32]. There is scant research linking ME/CFS to the common cold or flu-like infections, though upper respiratory infections are often reported as preceding the development of disabling fatigue in clinical practice. Our findings suggest a risk association, based on self-report. Clark et al. found a history of colds in childhood (at age 7 or 11) increased the risk of ME/CFS later in life (ORs ranged from 1.6 to 1.9) [33]. The predictive role of pre-morbid stress and infection is frequently reported in ME/CFS [34]. The exact cumulative impact of these two factors is uncertain, although it is well established that chronic stress has a considerable depressive effect on immune status, perhaps rendering an individual more susceptible to chronic infection. It is known that herpes viruses (HSV1 and HSV2, HHV6) are associated with a range of acute and chronic illnesses including, encephalitis/meningitis, shingles, chicken pox (Varicella Zoster), mononucleosis (Epstein Barr Virus), Kaposi's sarcoma (HHV8); and hearing loss, mental retardation with cytomegalovirus (HMCV) [30, 35]. Viral infections may disrupt mitochondrial function, resulting in fatigue; a cardinal 
Table 2 Description of participants from the UK ME/CFS Biobank, by category of recruitment and variables under the following domains: demographic, socio-economic, family health history, lifestyle, previous morbidity (prior disease onset for the diseased groups), and recent exposures

\begin{tabular}{|c|c|c|c|c|c|c|c|c|c|c|}
\hline \multirow[t]{3}{*}{ Domains } & \multirow[t]{3}{*}{ Variables } & & \multicolumn{6}{|c|}{ Category of Recruitment } & \multirow{2}{*}{\multicolumn{2}{|c|}{ Total }} \\
\hline & & & \multicolumn{2}{|c|}{$\begin{array}{l}\text { Healthy } \\
\text { control }\end{array}$} & \multicolumn{2}{|c|}{ MS control } & \multicolumn{2}{|c|}{ ME/CFSmm } & & \\
\hline & & & (n) & $(\%)$ & (n) & $(\%)$ & (n) & (\%) & (n) & (\%) \\
\hline \multirow[t]{13}{*}{ Demographic } & \multirow[t]{2}{*}{ Sex } & Male & 51 & 38.1 & 16 & 21.6 & 63 & 23.4 & 130 & 27.3 \\
\hline & & Female & 83 & 61.9 & 58 & 78.4 & 206 & 76.6 & 347 & 72.7 \\
\hline & \multirow[t]{4}{*}{ Age group } & $>=18 \&<30$ & 22 & 16.4 & 1 & 1.4 & 43 & 16.0 & 66 & 13.8 \\
\hline & & $>=30 \&<40$ & 33 & 24.6 & 12 & 16.2 & 60 & 22.3 & 105 & 22.0 \\
\hline & & $>=40 \&<50$ & 35 & 26.1 & 18 & 24.3 & 75 & 27.9 & 128 & 26.8 \\
\hline & & $>=50 \&<=60$ & 44 & 32.8 & 43 & 58.1 & 91 & 33.8 & 178 & 37.3 \\
\hline & \multirow[t]{5}{*}{ Incidence age group } & $<18$ & $n / a$ & $\mathrm{n} / \mathrm{a}$ & 3 & 4.2 & 42 & 16.7 & 45 & 14.0 \\
\hline & & $>=18 \&<30$ & $\mathrm{n} / \mathrm{a}$ & $\mathrm{n} / \mathrm{a}$ & 19 & 26.8 & 88 & 35.1 & 107 & 33.2 \\
\hline & & $>=30 \&<40$ & $\mathrm{n} / \mathrm{a}$ & $\mathrm{n} / \mathrm{a}$ & 22 & 31.0 & 61 & 24.3 & 83 & 25.8 \\
\hline & & $>=40 \&<50$ & $\mathrm{n} / \mathrm{a}$ & $\mathrm{n} / \mathrm{a}$ & 22 & 31.0 & 49 & 19.5 & 71 & 22.0 \\
\hline & & $>=50 \&<=60$ & $\mathrm{n} / \mathrm{a}$ & $\mathrm{n} / \mathrm{a}$ & 5 & 7.0 & 11 & 4.4 & 16 & 5.0 \\
\hline & \multirow[t]{2}{*}{ Ethnicity } & White & 119 & 91.5 & 70 & 94.6 & 247 & 96.5 & 436 & 94.8 \\
\hline & & Other & 11 & 8.5 & 4 & 5.4 & 9 & 3.5 & 24 & 5.2 \\
\hline \multirow[t]{15}{*}{ Socio-economic } & \multirow[t]{2}{*}{ Current marital status } & Married/with partner & 98 & 76.6 & 52 & 72.2 & 141 & 54.9 & 291 & 63.7 \\
\hline & & Single & 30 & 23.4 & 20 & 27.8 & 116 & 45.1 & 166 & 36.3 \\
\hline & \multirow[t]{3}{*}{ Marital status (prior disease onset) } & Married/with partner & $\mathrm{n} / \mathrm{a}$ & $\mathrm{n} / \mathrm{a}$ & 56 & 76.0 & 115 & 44.8 & 171 & 51.8 \\
\hline & & Divorced/separated & $n / a$ & $\mathrm{n} / \mathrm{a}$ & 5 & 6.7 & 26 & 10.1 & 31 & 9.4 \\
\hline & & Single & $\mathrm{n} / \mathrm{a}$ & $\mathrm{n} / \mathrm{a}$ & 12 & 17.3 & 116 & 45.1 & 128 & 38.8 \\
\hline & \multirow[t]{3}{*}{ Education } & Up to high school & 37 & 28.9 & 28 & 38.9 & 93 & 36.5 & 158 & 34.7 \\
\hline & & Started HE & 13 & 10.2 & 11 & 15.3 & 40 & 15.7 & 64 & 14.1 \\
\hline & & Completed HE/PG & 78 & 60.9 & 33 & 45.8 & 122 & 47.8 & 233 & 51.2 \\
\hline & \multirow[t]{2}{*}{ Individual income (current) } & Higher than $£ 19,999$ & 63 & 51.6 & 28 & 43.8 & 40 & 16.7 & 131 & 30.8 \\
\hline & & Up to $£ 19,999$ & 59 & 48.4 & 36 & 56.2 & 199 & 83.3 & 294 & 69.2 \\
\hline & \multirow[t]{3}{*}{ Individual income (prior disease onset) } & Higher than $£ 19,999$ & $\mathrm{n} / \mathrm{a}$ & $\mathrm{n} / \mathrm{a}$ & 36 & 56.2 & 67 & 28.8 & 103 & 34.7 \\
\hline & & Up to $£ 19,999$ & $\mathrm{n} / \mathrm{a}$ & $\mathrm{n} / \mathrm{a}$ & 28 & 43.8 & 166 & 71.2 & 194 & 65.3 \\
\hline & & & mean & SD & mean & SD & mean & SD & & \\
\hline & \multirow[t]{2}{*}{ Index of multiple deprivation ${ }^{a}$} & Deciles & 5.9 & 2.6 & 5.8 & 2.6 & 5.8 & 2.6 & & \\
\hline & & & (n) & $(\%)$ & (n) & $(\%)$ & (n) & (\%) & (n) & (\%) \\
\hline \multirow{12}{*}{$\begin{array}{l}\text { Family health } \\
\text { history }\end{array}$} & \multirow[t]{2}{*}{ High blood pressure } & No & 69 & 54.3 & 39 & 56.5 & 116 & 47.4 & 224 & 50.8 \\
\hline & & Yes & 58 & 45.7 & 30 & 43.5 & 129 & 52.7 & 217 & 49.2 \\
\hline & \multirow[t]{2}{*}{ Diabetes } & No & 102 & 81.0 & 49 & 70.0 & 178 & 73.6 & 329 & 75.1 \\
\hline & & Yes & 24 & 19.1 & 21 & 30.0 & 64 & 26.5 & 109 & 24.9 \\
\hline & Heart problems & No & 85 & 68.0 & 44 & 62.0 & 147 & 59.8 & 276 & 62.4 \\
\hline & & Yes & 40 & 32.0 & 27 & 38.0 & 99 & 40.2 & 166 & 37.6 \\
\hline & Asthma & No & 93 & 74.4 & 48 & 68.6 & 140 & 58.3 & 281 & 64.6 \\
\hline & & Yes & 32 & 25.6 & 22 & 31.4 & 100 & 41.7 & 154 & 35.4 \\
\hline & Allergies & No & 72 & 57.6 & 49 & 72.1 & 98 & 40.8 & 219 & 50.6 \\
\hline & & Yes & 53 & 42.4 & 19 & 27.9 & 142 & 59.2 & 214 & 49.4 \\
\hline & Depression & No & 80 & 64.0 & 48 & 66.7 & 132 & 54.3 & 260 & 59.1 \\
\hline & & Yes & 45 & 36.0 & 24 & 33.3 & 111 & 45.7 & 180 & 40.9 \\
\hline
\end{tabular}


Table 2 Description of participants from the UK ME/CFS Biobank, by category of recruitment and variables under the following domains: demographic, socio-economic, family health history, lifestyle, previous morbidity (prior disease onset for the diseased groups), and recent exposures (Continued)

\begin{tabular}{|c|c|c|c|c|c|c|c|c|c|c|}
\hline \multirow[t]{3}{*}{ Domains } & \multirow[t]{3}{*}{ Variables } & & \multicolumn{6}{|c|}{ Category of Recruitment } & \multirow{2}{*}{\multicolumn{2}{|c|}{ Total }} \\
\hline & & & \multicolumn{2}{|l|}{$\begin{array}{l}\text { Healthy } \\
\text { control }\end{array}$} & \multicolumn{2}{|c|}{ MS control } & \multicolumn{2}{|c|}{ ME/CFSmm } & & \\
\hline & & & (n) & $(\%)$ & (n) & $(\%)$ & (n) & $(\%)$ & (n) & $(\%)$ \\
\hline & \multirow[t]{2}{*}{ Anxiety } & No & 101 & 80.8 & 49 & 70.0 & 131 & 54.4 & 281 & 64.5 \\
\hline & & Yes & 24 & 19.2 & 21 & 30.0 & 110 & 45.6 & 155 & 35.6 \\
\hline & \multirow[t]{2}{*}{ Mental health problems } & No & 106 & 84.8 & 59 & 83.1 & 182 & 75.8 & 347 & 79.6 \\
\hline & & Yes & 19 & 15.2 & 12 & 16.9 & 58 & 24.2 & 89 & 20.4 \\
\hline & \multirow[t]{2}{*}{ Learning disabilities } & No & 93 & 97.9 & 66 & 93.0 & 127 & 88.2 & 286 & 92.3 \\
\hline & & Yes & 2 & 2.1 & 5 & 7.0 & 17 & 11.8 & 24 & 7.7 \\
\hline & \multirow[t]{2}{*}{ Physical disabilities } & No & 88 & 92.6 & 62 & 87.3 & 120 & 83.9 & 270 & 87.4 \\
\hline & & Yes & 7 & 7.4 & 9 & 12.7 & 23 & 16.1 & 39 & 12.6 \\
\hline & \multirow[t]{2}{*}{ Cancer } & No & 77 & 61.1 & 30 & 41.7 & 144 & 60.0 & 251 & 57.3 \\
\hline & & Yes & 49 & 38.9 & 42 & 58.3 & 96 & 40.0 & 187 & 42.7 \\
\hline & \multirow[t]{2}{*}{ ME/CFS } & No & 117 & 94.4 & 67 & 97.1 & 214 & 89.9 & 398 & 92.3 \\
\hline & & Yes & 7 & 5.7 & 2 & 2.9 & 24 & 10.1 & 33 & 7.7 \\
\hline & \multirow[t]{2}{*}{ MS } & No & 94 & 99.0 & 60 & 85.7 & 137 & 97.9 & 291 & 95.4 \\
\hline & & Yes & 1 & 1.1 & 10 & 14.3 & 3 & 2.1 & 14 & 4.6 \\
\hline & \multirow[t]{2}{*}{ Other neurological problems } & No & 87 & 91.6 & 64 & 90.1 & 117 & 83.0 & 268 & 87.3 \\
\hline & & Yes & 8 & 8.4 & 7 & 9.9 & 24 & 17.0 & 39 & 12.7 \\
\hline & \multirow[t]{2}{*}{ Tuberculosis } & No & 93 & 97.9 & 61 & 88.4 & 136 & 95.8 & 290 & 94.8 \\
\hline & & Yes & 2 & 2.1 & 8 & 11.6 & 6 & 4.2 & 16 & 5.2 \\
\hline & \multirow[t]{2}{*}{ Any other health problems } & No & 91 & 73.4 & 48 & 68.6 & 107 & 45.7 & 246 & 57.5 \\
\hline & & Yes & 33 & 26.6 & 22 & 31.4 & 127 & 54.3 & 182 & 42.5 \\
\hline \multirow[t]{10}{*}{ Lifestyle } & & & median & $\mathrm{IQR}$ & median & $\mathrm{IQR}$ & median & $\mathrm{IQR}$ & & \\
\hline & Alcohol consumption & Currently (units/week) & 4 & $\begin{array}{l}1- \\
10\end{array}$ & 2 & $0-9$ & 0 & $\begin{array}{l}0- \\
2\end{array}$ & $\mathrm{n} / \mathrm{a}$ & $\mathrm{n} / \mathrm{a}$ \\
\hline & \multirow[t]{2}{*}{ Alcohol consumption } & \multirow[t]{2}{*}{$\begin{array}{l}\text { Prior disease onset (units/ } \\
\text { week) }\end{array}$} & $\mathrm{n} / \mathrm{a}$ & n/a & 3 & $\begin{array}{l}0- \\
10\end{array}$ & 2 & $\begin{array}{l}0- \\
7\end{array}$ & $\mathrm{n} / \mathrm{a}$ & $\mathrm{n} / \mathrm{a}$ \\
\hline & & & $(n)$ & $(\%)$ & $(n)$ & (\%) & (n) & (\%) & $(n)$ & (\%) \\
\hline & \multirow[t]{3}{*}{ Smoking status } & Never smoke & 85 & 65.4 & 30 & 40.5 & 159 & 62.1 & 274 & 59.6 \\
\hline & & Ex-smoker & 39 & 30.0 & 26 & 35.1 & 66 & 25.8 & 131 & 28.5 \\
\hline & & Current smoker & 6 & 4.6 & 18 & 24.3 & 31 & 12.1 & 55 & 12.0 \\
\hline & Physical activity level & Rather inactive/not active & 19 & 14.6 & 7 & 9.5 & 13 & 5.1 & 39 & 8.5 \\
\hline & & Neither active nor inactive & 23 & 17.7 & 11 & 14.9 & 23 & 9.0 & 57 & 12.4 \\
\hline & & Very active/rather active & 88 & 67.7 & 56 & 75.7 & 219 & 85.9 & 363 & 79.1 \\
\hline Previous morbidity & High blood pressure & No & 118 & 90.8 & 68 & 95.8 & 240 & 95.2 & 426 & 94.0 \\
\hline & & Yes & 12 & 9.2 & 3 & 4.2 & 12 & 4.8 & 27 & 6.0 \\
\hline & Heart problems & No & 125 & 96.9 & 70 & 98.6 & 242 & 96.0 & 437 & 96.7 \\
\hline & & Yes & 4 & 3.1 & 1 & 1.4 & 10 & 4.0 & 15 & 3.3 \\
\hline & Asthma & No & 115 & 90.6 & 66 & 91.7 & 187 & 74.2 & 368 & 81.6 \\
\hline & & Yes & 12 & 9.5 & 6 & 8.3 & 65 & 25.8 & 83 & 18.4 \\
\hline & Allergies & No & 67 & 51.9 & 49 & 67.1 & 143 & 57.7 & 259 & 57.6 \\
\hline & & Yes & 62 & 48.1 & 24 & 32.9 & 105 & 42.3 & 191 & 42.4 \\
\hline & Depression & No & 113 & 86.9 & 57 & 78.1 & 157 & 62.1 & 327 & 71.7 \\
\hline
\end{tabular}


Table 2 Description of participants from the UK ME/CFS Biobank, by category of recruitment and variables under the following domains: demographic, socio-economic, family health history, lifestyle, previous morbidity (prior disease onset for the diseased groups), and recent exposures (Continued)

\begin{tabular}{|c|c|c|c|c|c|c|c|c|c|c|}
\hline \multirow[t]{3}{*}{ Domains } & \multirow[t]{3}{*}{ Variables } & & \multicolumn{6}{|c|}{ Category of Recruitment } & \multirow{2}{*}{\multicolumn{2}{|c|}{ Total }} \\
\hline & & & \multicolumn{2}{|c|}{$\begin{array}{l}\text { Healthy } \\
\text { control }\end{array}$} & \multicolumn{2}{|c|}{ MS control } & \multicolumn{2}{|c|}{ ME/CFSmm } & & \\
\hline & & & (n) & $(\%)$ & (n) & $(\%)$ & (n) & $(\%)$ & (n) & (\%) \\
\hline & & Yes & 17 & 13.1 & 16 & 21.9 & 96 & 37.9 & 129 & 28.3 \\
\hline & Anxiety & No & 100 & 76.9 & 57 & 78.1 & 153 & 60.2 & 310 & 67.8 \\
\hline & & Yes & 30 & 23.1 & 16 & 21.9 & 101 & 39.8 & 147 & 32.2 \\
\hline & High levels of stress & No & 75 & 57.7 & 36 & 50.7 & 106 & 42.4 & 217 & 48.1 \\
\hline & & Yes & 55 & 42.3 & 35 & 49.3 & 144 & 57.6 & 234 & 51.9 \\
\hline & Frequent coughs/colds & No & 122 & 93.9 & 62 & 88.6 & 155 & 61.8 & 339 & 75.2 \\
\hline & & Yes & 8 & 6.2 & 8 & 11.4 & 96 & 38.3 & 112 & 24.8 \\
\hline & Intolerance to alcoholic drinks & No & 121 & 94.5 & 71 & 100.0 & 213 & 88.4 & 405 & 92.1 \\
\hline & & Yes & 7 & 5.5 & 0 & 0.0 & 28 & 11.6 & 35 & 8.0 \\
\hline & Intolerance to sugar & No & 129 & 99.2 & 72 & 100.0 & 235 & 94.8 & 436 & 96.9 \\
\hline & & Yes & 1 & 0.8 & 0 & 0.0 & 13 & 5.2 & 14 & 3.1 \\
\hline & Other health problems & No & 111 & 89.5 & 60 & 89.6 & 166 & 81.8 & 337 & 85.5 \\
\hline & & Yes & 13 & 10.5 & 7 & 10.5 & 37 & 18.2 & 57 & 14.5 \\
\hline \multirow[t]{27}{*}{ Recent exposures } & Lived on a farm & No & 126 & 96.9 & 68 & 95.8 & 238 & 94.1 & 432 & 95.2 \\
\hline & & Yes & 4 & 3.1 & 3 & 4.2 & 11 & 4.4 & 18 & 4.0 \\
\hline & & Don't know & 0 & 0.0 & 0 & 0.0 & 4 & 1.6 & 4 & 0.9 \\
\hline & Tick bites & No & 71 & 98.6 & 25 & 96.2 & 78 & 86.7 & 174 & 92.6 \\
\hline & & Yes & 0 & 0.0 & 0 & 0.0 & 1 & 1.1 & 1 & 0.5 \\
\hline & & Don't know & 1 & 1.4 & 1 & 3.9 & 11 & 12.2 & 13 & 6.9 \\
\hline & Vaccines/immunisations & No & 67 & 93.1 & 19 & 73.1 & 80 & 88.9 & 166 & 88.3 \\
\hline & & Yes & 5 & 6.9 & 7 & 26.9 & 8 & 8.9 & 20 & 10.6 \\
\hline & & Don't know & 0 & 0.0 & 0 & 0.0 & 2 & 2.2 & 2 & 1.1 \\
\hline & Travelled overseas & No & 69 & 53.1 & 39 & 53.4 & 150 & 59.3 & 258 & 56.6 \\
\hline & & Yes & 61 & 46.9 & 31 & 42.5 & 87 & 34.4 & 179 & 39.3 \\
\hline & & Don't know & 0 & 0.0 & 3 & 4.1 & 16 & 6.3 & 19 & 4.2 \\
\hline & Flooding & No & 128 & 98.5 & 73 & 98.7 & 250 & 97.7 & 451 & 98.0 \\
\hline & & Yes & 2 & 1.5 & 1 & 1.4 & 3 & 1.2 & 6 & 1.3 \\
\hline & & Don't know & 0 & 0.0 & 0 & 0.0 & 3 & 1.2 & 3 & 0.7 \\
\hline & Radiation & No & 71 & 98.6 & 25 & 96.2 & 82 & 91.1 & 178 & 94.7 \\
\hline & & Yes & 1 & 1.4 & 1 & 3.9 & 4 & 4.4 & 6 & 3.2 \\
\hline & & & 0 & 0.0 & 0 & 0.0 & 4 & 4.4 & 4 & 2.1 \\
\hline & Carbon monoxide (CO) & No & 128 & 97.7 & 68 & 89.5 & 210 & 81.4 & 406 & 87.3 \\
\hline & & Yes & 1 & 0.8 & 0 & 0.0 & 3 & 1.2 & 4 & 0.9 \\
\hline & & Don't know & 2 & 1.5 & 8 & 10.5 & 45 & 17.4 & 55 & 11.8 \\
\hline & Pesticides & No & 119 & 92.3 & 57 & 77.0 & 174 & 68.2 & 350 & 76.4 \\
\hline & & Yes & 2 & 1.6 & 2 & 2.7 & 18 & 7.1 & 22 & 4.8 \\
\hline & & Don't know & 8 & 6.2 & 15 & 20.3 & 63 & 24.7 & 86 & 18.8 \\
\hline & Any other chemicals & No & 118 & 91.5 & 54 & 73.0 & 158 & 62.2 & 330 & 72.2 \\
\hline & & Yes & 6 & 4.7 & 3 & 4.1 & 25 & 9.8 & 34 & 7.4 \\
\hline & & Don't know & 5 & 3.9 & 17 & 23.0 & 71 & 28.0 & 93 & 20.4 \\
\hline
\end{tabular}


Table 2 Description of participants from the UK ME/CFS Biobank, by category of recruitment and variables under the following domains: demographic, socio-economic, family health history, lifestyle, previous morbidity (prior disease onset for the diseased groups), and recent exposures (Continued)

\begin{tabular}{|c|c|c|c|c|c|c|c|c|c|c|}
\hline \multirow[t]{3}{*}{ Domains } & \multirow[t]{3}{*}{ Variables } & & \multicolumn{6}{|c|}{ Category of Recruitment } & \multirow{2}{*}{\multicolumn{2}{|c|}{ Total }} \\
\hline & & & \multicolumn{2}{|c|}{$\begin{array}{l}\text { Healthy } \\
\text { control }\end{array}$} & \multicolumn{2}{|c|}{ MS control } & \multicolumn{2}{|c|}{ ME/CFSmm } & & \\
\hline & & & (n) & (\%) & (n) & $(\%)$ & (n) & $(\%)$ & (n) & $(\%)$ \\
\hline & \multirow[t]{3}{*}{ Had meningitis } & No & 130 & 100.0 & 73 & 98.7 & 247 & 96.5 & 450 & 97.8 \\
\hline & & Yes & 0 & 0.0 & 1 & 1.4 & 2 & 0.8 & 3 & 0.7 \\
\hline & & Don't know & 0 & 0.0 & 0 & 0.0 & 7 & 2.7 & 7 & 1.5 \\
\hline & \multirow[t]{3}{*}{ Had any other serious infection } & No & 128 & 98.5 & 65 & 89.0 & 167 & 67.9 & 360 & 80.2 \\
\hline & & Yes & 2 & 1.5 & 6 & 8.2 & 62 & 25.2 & 70 & 15.6 \\
\hline & & Don't know & 0 & 0.0 & 2 & 2.7 & 17 & 6.9 & 19 & 4.2 \\
\hline & \multirow[t]{3}{*}{ Had any head injury } & No & 129 & 100.0 & 65 & 89.0 & 229 & 89.8 & 423 & 92.6 \\
\hline & & Yes & 0 & 0.0 & 6 & 8.2 & 16 & 6.3 & 22 & 4.8 \\
\hline & & Don't know & 0 & 0.0 & 2 & 2.7 & 10 & 3.9 & 12 & 2.6 \\
\hline & \multirow[t]{3}{*}{ Had a major operation } & No & 128 & 99.2 & 68 & 91.9 & 235 & 92.2 & 431 & 94.1 \\
\hline & & Yes & 1 & 0.8 & 6 & 8.1 & 15 & 5.9 & 22 & 4.8 \\
\hline & & Don't know & 0 & 0.0 & 0 & 0.0 & 5 & 2.0 & 5 & 1.1 \\
\hline & \multirow[t]{3}{*}{ Contraceptive pill (women only) } & No & 67 & 52.8 & 33 & 45.8 & 139 & 55.4 & 239 & 53.1 \\
\hline & & Yes & 16 & 12.6 & 23 & 31.9 & 63 & 25.1 & 102 & 22.7 \\
\hline & & Don't know & 3 & 2.4 & 0 & 0.0 & 4 & 1.6 & 7 & 1.6 \\
\hline & \multirow{3}{*}{$\begin{array}{l}\text { Lived in a house with gas or oil } \\
\text { appliances }\end{array}$} & No & 28 & 21.5 & 24 & 32.9 & 50 & 19.8 & 102 & 22.4 \\
\hline & & Yes & 102 & 78.5 & 49 & 67.1 & 201 & 79.8 & 352 & 77.4 \\
\hline & & Don't know & 0 & 0.0 & 0 & 0.0 & 1 & 0.4 & 1 & 0.2 \\
\hline & \multirow[t]{3}{*}{ Lived in a house with a gas fire } & No & 100 & 77.5 & 46 & 63.9 & 153 & 61.0 & 299 & 66.2 \\
\hline & & Yes & 29 & 22.5 & 26 & 36.1 & 97 & 38.7 & 152 & 33.6 \\
\hline & & Don't know & 0 & 0.0 & 0 & 0.0 & 1 & 0.4 & 1 & 0.2 \\
\hline & \multirow[t]{3}{*}{ BCG vaccination } & No & 17 & 17.4 & 24 & 32.9 & 26 & 17.1 & 67 & 20.7 \\
\hline & & Yes & 63 & 64.3 & 41 & 56.2 & 97 & 63.8 & 201 & 62.2 \\
\hline & & Don't know & 18 & 18.4 & 8 & 11.0 & 29 & 19.1 & 55 & 17.0 \\
\hline
\end{tabular}

MS - multiple sclerosis; ME/CFS - Myalgic Encephalomyelitis/Chronic Fatigue Syndrome; HE - Higher education; HE/ PG - Higher education/post-graduation; andex of multiple deprivation (IDM) is the measure of relative deprivation for small areas in England (official measure). It is composed by the following indices: Income Deprivation (22.5\%), Employment Deprivation (22.5\%), Education, Skills and Training Deprivation (13.5\%), Health Deprivation and Disability (13.5\%), Crime (9.3\%), Barriers to Housing and Services (9.3\%), and Living Environment Deprivation (9.3\%). IDM decile 1 refers to the most deprived area and decile 10 to the least deprived area (https://assets.publishing.service.gov.uk/government/uploads/system/uploads/attachment_data/file/464430/English_Index_of_Multiple_ Deprivation 2015 - Guidance.pdf)

symptom of ME/CFS, and initiate an array of inflammatory responses in ME/CFS $[7,8]$ that help explain the pain and other symptoms experienced by people with ME/CFS. Two studies reveal clustering of cases in UK schools [36, 37] giving credence to the role of infectious aetiology in ME/CFS in adolescents/children. Historically there have been reports of ME-type cluster outbreaks in adults in defined geographical areas, such as Los Angeles (poliomyelitis - 1934), Iceland (1948 - Icelandic disease), Royal Free Disease, (London, UK 1955 benign myalgic encephalomyelitis), Florida (epidemic neuromyasthenia - 1957), New Zealand (Tapanuni flu - 1983), Nevada (Lake Tahoe 1984 - chronic fatigue syndrome). A more recent outbreak in Bergen, Norway
(2004) accounted for cases of ME/CFS-like illness following infection with Giardia enteritis [38]. Assuming equal exposure risk to common infectious agents for males and females, with higher female dominance, we speculate that genotype and the host response, including hormonal mediation, are important risk factors.

Our finding that being single or separated/divorced is associated with ME/CFS may be reverse causal, as ME/CFS often severely impacts physical health and restricts social functional ability [39]. Other studies have also found that participants with ME/CFS are more likely to be unmarried compared to healthy counterparts [23]. Reverse causality may also be the reason for lower income reported by people with ME/CFS, which have previously discussed [39]. 
Table 3 List of variables included in the multivariable analyses, by comparison groups and levels of hierarchy

\begin{tabular}{|c|c|}
\hline Domain & $\begin{array}{l}\text { Significant variables resulting from the bivariate analyses, included in the } \\
\text { multivariable models }(p \leq 0.10)\end{array}$ \\
\hline \multicolumn{2}{|c|}{ Multivariable analysis 1 - Comparison between people with ME/CFS and healthy controls } \\
\hline Level 1 - Demographic & Age at survey, sex, ethnicity \\
\hline Level 2 - Socio-Economic & Marital status, education, income \\
\hline Level 3 - Family Health History & $\begin{array}{l}\text { Asthma, allergies, depression, anxiety, learning disabilities, mental health } \\
\text { issues, physical disabilities, other health problems, other neurologic problems }\end{array}$ \\
\hline Level 4 - Lifestyle & Smoking status, alcohol consumption/week, physical activity previous 6 months \\
\hline Level 5 - Previous Morbidity (prior to disease onset) & $\begin{array}{l}\text { Asthma, depression, anxiety, stress, colds, alcohol intolerance, sugar intolerance, } \\
\text { other health problems }\end{array}$ \\
\hline Level 6 - Recent Exposures (6 months prior to disease onset) & $\begin{array}{l}\text { Travelling, pesticides, chemicals, infection(s), pill contraception, surgery(ies), } \\
\text { and gas fire appliances in the home }\end{array}$ \\
\hline \multicolumn{2}{|c|}{ Multivariable Analysis2 - Comparison between people with ME/CFS and people with MS } \\
\hline Level 1 - Demographic & Age at disease onset, sex, ethnicity \\
\hline Level 2 - Socio-Economic & Marital status, education, income, and occupation at 6 months previous onset \\
\hline Level 3 - Family Health History & Allergies, anxiety \\
\hline Level 4 - Lifestyle & Alcohol consumption/week, physical activity previous 6 months \\
\hline Level 5 - Previous Morbidity (prior to disease onset) & $\begin{array}{l}\text { Asthma, allergies, depression, anxiety, stress, colds, alcohol intolerance, } \\
\text { sugar intolerance, other health problems }\end{array}$ \\
\hline Level 6 - Recent Exposures ( 6 months prior to disease onset) & Infection, BCG vaccine \\
\hline
\end{tabular}

ME/CFS Myalgic Encephalomyelitis/Chronic Fatigue Syndrome, MS Multiple Sclerosis.

We found an association between reports of family history of anxiety and ME/CFS, but not with personal history of anxiety. It has been reported that people with ME/CFS often have a higher prevalence of psychiatric comorbidities, primarily depression and anxiety disorder [40], and that ME/CFS is associated with higher levels of psychological distress compared with other chronic illness states, such as rheumatoid arthritis [41]; however we did not find a higher reported personal history of either depression or anxiety disorder in people with ME/CFS. We can argue that minor psychiatric morbidity may well reflect the consequences of living with a disabling chronic disease. There is inconsistent evidence whether or not primary psychiatric disorder is a significant risk factor in ME/CFS [40]. One complication with studies of pre-morbid risk in ME/CFS is that ME/CFS patients commonly wait many years to get an affirmative diagnosis, thus studies of pre-diagnostic illness may be detecting psychopathology secondary to the uncertainty of a diagnosis, and "unexplained" symptoms. In addition, given the overlap that exists between the symptoms of ME/CFS and psychiatric disorders, (fatigue, low mood, poor sleep) misdiagnosis may be considerable. In a study of 279 patients referred to a Belgium clinic with suspected chronic fatigue syndrome, $45.2 \%$ were diagnosed with a mood or anxiety disorder, yet only $23.3 \%$ of the entire cohort eventually received an unequivocal CFS diagnosis [42]. In a UK study of referrals to a specialist CFS treatment centre, out of 260 patient referrals examined, $40 \%$ of these did not have CFS but other medical and psychiatric illnesses [43].

\section{ME/CFS versus MS}

ME/CFS cases were shown to be more likely to have a history of colds and other infections 6 months prior

Table 4 Final multivariable model, comparing participants with ME/CFS and healthy controls $(n=324)$

\begin{tabular}{lllll}
\hline Variables & Odds Ratio & Standard Error & $95 \%$ Confidence Interval & $P$ value \\
\hline Age at survey (in years) $_{\text {Lower income }^{\text {a }}}$ & 1.05 & 0.01 & $1.02-1.08$ & 0.003 \\
Marital status - separated or divorced $^{\text {b }}$ & 3.71 & 1.18 & $1.10-6.92$ & $<=0.001$ \\
Marital status - single $^{\text {b }}$ & 1.84 & 1.02 & $0.62-5.47$ & 0.275 \\
Family history of anxiety $_{\text {History of frequent colds/flu }}$ & 4.41 & 1.77 & $2.00-9.71$ & $1.98-7.16$ \\
Infection(s) 6 months before disease onset & 3.77 & 1.23 & $3.64-18-77$ & $<=0.001$ \\
\hline
\end{tabular}

ME/CFS Myalgic Encephalomyelitis/Chronic Fatigue Syndrome.

${ }^{a}$ Up to Up to $£ 19,999 /$ year; ${ }^{b}$ the refence category is married/with partner, i.e. in a stable relationship 
Table 5 Final multivariable model, comparing participants with ME/CFS and participants with MS $(n=273)$

\begin{tabular}{|c|c|c|c|c|}
\hline Variables & Odds Ratio & Standard Error & 95\% Confidence Interval & $P$ value \\
\hline Age at disease onset (in years) & 0.95 & 0.02 & $0.92-0.99$ & 0.016 \\
\hline Lower income $^{a}$ & 3.48 & 1.27 & $1.70-7.13$ & 0.001 \\
\hline Marital status - separated or divorced ${ }^{b}$ & 2.26 & 1.61 & $0.56-9.12$ & 0.250 \\
\hline Marital status - single ${ }^{b}$ & 3.66 & 1.62 & $1.54-8.72$ & 0.003 \\
\hline History of frequent colds/flu & 6.31 & 3.16 & $2.36-16.86$ & $<0.001$ \\
\hline Infection(s) 6 months before disease onset & 5.12 & 2.97 & $1.66-15.98$ & 0.005 \\
\hline
\end{tabular}

ME/CFS Myalgic Encephalomyelitis/Chronic Fatigue Syndrome.

a Up to Up to $£ 19,999 /$ year; ${ }^{b}$ the refence category is married/with partner, i.e. in a stable relationship

to disease onset than MS cases; which is consistent with the findings of comparing ME/CFS with healthy controls, and with the current theories of predisposing/trigger factors (see section above). Tentative links have also been made between MS and human herpes viruses (HHV-6 and EBV) [44]. As in MS, no causal link between one pathogenic agent and ME/CFS has been clearly established.

In addition, there was a larger proportion of people living with partners among people with MS than in people with ME/CFS; and lower income was also reported by people with ME/CFS, which we argue to be explained by reverse causality. This could also be partially related to the fact that people with ME/CFS were younger than MS cases at the time of developing disease symptoms.

\section{Mild-moderate versus severe ME/CFS}

Participants with more severe ME/CFS in our cohort were younger by an average of 4.5 years at disease onset and were more likely to report a family history of neurological problems. The association with age and illness severity may reflect the fact that younger sufferers who go on to have ME/CFS for longer periods, are more likely to have moderate to severe illness presentations. Norris et al. report a large-scale follow-up of adolescents with suspected chronic fatigue syndrome (age 13-18); 75\% spontaneously recover within 2-3 years [45], with a quarter with persistent disease. In a previous study, we reported on ME/CFS participants having more pronounced neuro-cognitive symptoms compared with MS participants [46]. The association between ME/ CFS and a family history of neurological illness points to genetic risk factors and/or environmental exposure risk; such findings require much more detailed investigation, such as on the confirmation of the diagnosis in the relative and the inclusion of a more formal family history investigation with family pedigrees. We must also consider the ways in which ME/CFS participants recount their symptom experience compared with the ways in which people with MS participants experience illness; ME/CFS patients often have limited medical support, whereas MS is a recognised neurological disease for which there is specialist NHS support, and this may affect the reliability of the information reported by the individual.

\section{Strengths and limitations}

The presence in the final predictive models of variables from all the levels defined in the conceptual approach shows that the occurrence of ME/CFS is the result of a complex multi-factorial process, which includes fixed factors such as age and heredity, and variable factors such as exposure to pathogens. By using a modelling approach involving different factor domains potentially associated with ME/CFS, we have been able to present the relative importance of different risk factors that are often reported in the literature in isolation. Our multivariable analyses helps to capture how different factors jointly contribute to predict ME/CFS, with some factors being distal (e.g. age or income) and some factors being proximal (e.g. recent infection experience). This type of conceptual approach is useful for theorising ME/CFS aetiology, but is biased by the selective inclusion and exclusion of factors investigated. Other risk factors not studied may also be relevant, such as alternative infectious agents, for example. Recall bias is also a major issue, which is likely to be differential, particularly when people with ME/CFS are compared to healthy controls. Data collected from ME/CFS and MS participants relate to a period before they became ill, and there is no equivalent period space for healthy controls, making comparisons challenging between these groups. Nevertheless, healthy control populations offer a reasonable comparison group. Also, the data result from a survey where only a small fraction of the individuals reached by the survey has responded and it is not possible to guarantee or ascertain that this is a representative sample of the targeted population. From the point of view of model building, the conceptual model selected the variables in a manner that aimed to reduce the number of variables in the predictive model; and, by reducing the number of variables we also reduced the impact of missing values on predictive power. However, our model did not consider non-linear terms/ 
interactions and this may be a reason why the goodness of fit chi squared test reached significance for the comparison with MS, and the specificity was very low (besides the smaller sample size of MS cases in comparison with the healthy controls).

We believe that if the conceptual model we used in this study is applied to well-designed prospective cohorts with larger sample size, some of the limitations described would be overcome, and more significant contributions to knowledge of the factors predictive of ME/ CFS could be made.

\section{Conclusions}

Our findings suggest a stronger risk association between exposure to common viral infections (colds/flu) and ME/CFS than seen in the literature. Additionally, we found that a recent history of infection prior to disease onset is associated with ME/CFS. Notable differences in risk profiles were found between participants with $\mathrm{ME} /$ CFS and healthy controls and ME/CFS and MS. However, we also found commensurate overlap in some risk factors between all cohorts. This suggests that while ME/CFS may share some similar risks with MS, there are notable differences, particularly the strong association with infection in ME/CFS. Our findings add to the increasing body of evidence on the role infections in the pathogenesis of ME/CFS.

\section{Supplementary information}

Supplementary information accompanies this paper at https://doi.org/10. 1186/s12883-019-1468-2.

Additional file 1. Participant Questionnaires.

\section{Abbreviations}

CCC: Canadian Consensus Criteria; CDC: Centres for Disease Control and Prevention; LSHTM: London School of Hygiene \& Tropical Medicine; ME/ CFS: Myalgic encephalomyelitis/chronic fatigue syndrome; MS: Multiple sclerosis; NHS: National Health Service; NICE: National Institute for Clinical Excellence; OR: Odds ratio; UKMEB: UK ME Biobank

\section{Acknowledgements}

We would like to express our sincere appreciation to our study participants: those with ME/CFS, those with MS, and our healthy controls, who so generously contributed to our UK ME/CFS Biobank. We also would like to thank Mr. João Malato, for his suggestions about the analytical approach used in this manuscript.

\section{Authors' contributions}

LN and EL conceptualised the study design and contributed to data collection, data cleaning, analysis, interpretation, and writing-up. KG has drafted the initial manuscript and contributed with interpretation of findings, CK has contributed with data collection, data interpretation, and substantial revision of the manuscript, LP significantly revised the data analysis, and contributed to the final version of the manuscript. All authors revised and approved the present version of the manuscript.

\section{Funding}

KG is currently in receipt of a small grant from the charity sector to research various topics in ME/CFS aetiology and treatment. The UK Biobank accepts funding and donations from the charity sector. Research reported was supported by the National Institute of Allergy and Infectious Diseases (NIAID) of the National Institutes of Health $(\mathrm{NIH})$ under Award Number: R01Al103629. EL, LN, LP and CK are funded by the NIAID/NIH; and LP, CK and LN are also funded by a grant from the ME Association (PF8947_ME Association).

The content of this paper is solely the responsibility of the authors and does not necessarily represent the official views of the NIH. The funding agencies did not have any role in the designing, data collection, data analysis, interpretation or writing-up the present manuscript.

\section{Availability of data and materials}

The datasets used and/or analysed during the current study are available from the corresponding author on reasonable request.

\section{Ethics approval and consent to participate}

Ethical approval was granted by the London School of Hygiene \& Tropical Medicine SHTM Ethics Committee January 16th, 2012 (Ref.6123) and the National Research Ethics Service (NRES) London- Bloomsbury Research Ethics Committee December 22nd, 2011 (REC ref. 11/10/1760, IRAS ID: 77765). All biobank participants provided written consent for questionnaire, clinical measurement, and laboratory test data, and samples to be made available for ethically-approved research, after receiving an extensive information sheet and consent form, which includes an option to withdraw from the study at any time.

\section{Consent for publication \\ Not applicable.}

\section{Competing interests}

The authors declare that they have no competing interests.

\section{Author details}

${ }^{1}$ Faculty of Infectious and Tropical Diseases, London School of Hygiene \& Tropical Medicine, London WC1E 7HT, UK. ${ }^{2}$ Centre for Primary Care, Institute of Population Health, School of Community Based Medicine, University of Manchester, Williamson Building, Brunswick Street, Manchester M13 9PL, UK.

Received: 14 August 2018 Accepted: 16 September 2019

Published online: 07 November 2019

\section{References}

1. Ramsay AM, Dowsett EG, Dadswell JV, Lyle WH, Parish JG. Icelandic disease (benign myalgic encephalomyelitis or Royal Free disease). Br Med J. 1977; 1(6072):1350.

2. Holmes GP, Kaplan JE, Gantz NM, Komaroff AL, Schonberger LB, Straus SE, et al. Chronic fatigue syndrome: a working case definition. Ann Intern Med. 1988:108(3):387-9.

3. Nacul LC, Lacerda EM, Pheby D, Campion P, Molokhia M, Fayyaz S, et al. Prevalence of myalgic encephalomyelitis/chronic fatigue syndrome (ME/ (FS) in three regions of England: a repeated cross-sectional study in primary care. BMC Med. 2011;9(1):91.

4. Baker R, Shaw E. Diagnosis and management of chronic fatigue syndrome or myalgic encephalomyelitis (or encephalopathy): summary of NICE guidance. BMJ. 2007;335:446-8.

5. Fukuda K, Straus S, Hickie I, Sharpe M, Dobbins J, Komaroff A. The chronic fatigue syndrome: a comprehensive approach to its definition and study. International chronic fatigue syndrome study group. Ann Intern Med. 1994; 121(12):953-9

6. Carruthers, Jain A, De Meirleir K, Peterson D, Klimas N, Lerner A, Bested A, Flor-Henry P, Joshi P, Peter Powles A et al. Myalgic Encephalomyelitis/ Chronic Fatigue Syndrome: Clinical Working Case Definition, Diagnostic and Treatment Protocols. J Chron Fatigue Synd. 2003;11 (1):7-97.

7. Montoya JG, Holmes TH, Anderson JN, Maecker HT, Rosenberg-Hasson Y, Valencia IJ, et al. Cytokine signature associated with disease severity in chronic fatigue syndrome patients. Proc Natl Acad Sci U S A. 2017;114(34): E7150-8.

8. Hornig M, Montoya JG, Klimas NG, Levine S, Felsenstein D, Bateman L, Peterson DL, Gottschalk CG, Schultz AF, Che X, Eddy ML, Komaroff AL, Lipkin WI. Distinct plasma immune signatures in ME/CFS are present early in the course of illness. Sci Adv. 2015;1(1):e1400121. https://doi.org/10.1126/sciadv. 1400121. 
9. Albright F, Light K, Light A, Bateman L, Cannon-Albright LA. Evidence for a heritable predisposition to chronic fatigue syndrome. BMC Neurol. 2011;11:62.

10. Underhill RA, O'Gorman R. Prevalence of chronic fatigue syndrome and chronic fatigue within families of CFS patients. J Chron Fatigue Synd. 2006; 13(1):3-13.

11. Schlauch KA, Khaiboullina SF, De Meirleir KL, Rawat S, Petereit J, Rizvanov $\mathrm{AA}$, et al. Genome-wide association analysis identifies genetic variations in subjects with myalgic encephalomyelitis/chronic fatigue syndrome. Transl Psychiatry. 2016;6:e730.

12. Hempel S, Chambers D, Bagnall AM, Forbes C. Risk factors for chronic fatigue syndrome/myalgic encephalomyelitis: a systematic scoping review of multiple predictor studies. Psychol Med. 2008;38(7):915-26.

13. Reyes M, Nisenbaum R, Hoaglin DC, Unger ER, Emmons C, Randall B, et al. Prevalence and incidence of chronic fatigue syndrome in Wichita, Kansas. Arch Intern Med. 2003;163(13):1530-6.

14. Underhill RA. Myalgic encephalomyelitis, chronic fatigue syndrome: an infectious disease. Med Hypotheses. 2015;85(6):765-73.

15. Taylor RR, Jason LA. Sexual abuse, physical abuse, chronic fatigue, and chronic fatigue syndrome: a community-based study. J Nerv Ment Dis. 2001; 189(10):709-15.

16. Heim C, Nater UM, Maloney E, Boneva R, Jones JF, Reeves WC. Childhood trauma and risk for chronic fatigue syndrome: association with neuroendocrine dysfunction. Arch Gen Psychiatry. 2009:66(1):72-80.

17. Lacerda EM, Bowman EW, Cliff JM, Kingdon CC, King EC, Lee J-S, et al. The UK ME/CFS biobank for biomedical research on Myalgic encephalomyelitis/ chronic fatigue syndrome (ME/CFS) and multiple sclerosis. Open J Biores. 2017:4(1):4.

18. Victora CG, Huttly SR, Fuchs SC, Olinto MT. The role of conceptual frameworks in epidemiological analysis: a hierarchical approach. Int J Epidemiol. 1997;26(1):224-7.

19. English indices of deprivation 2015 [https://www.gov.uk/government/ statistics/english-indices-of-deprivation-2015].

20. StataCorp LCC. Stata/IC 15.1 for windows (64-bit x86-64) in., vol. 08 may 2018, 15.1 edn. College Station: StataCorp LLC; 2018.

21. Johnston SC, Staines DR, Marshall-Gradisnik SM. Epidemiological characteristics of chronic fatique syndrome/myalgic encephalomyelitis in Australian patients. Clin Epidemiol. 2016;8:97-107.

22. Bakken I, Tveito K, Gunnes N, Ghaderi S, Stoltenberg C, Trogstad L, et al. Two age peaks in the incidence of chronic fatigue syndrome/myalgic encephalomyelitis: a population-based registry study from Norway 2008 inverted question mark2012. BMC Med. 2014;12(1):167.

23. Faro M, Saez-Francas N, Castro-Marrero J, Aliste L, Fernandez de Sevilla T, Alegre J. Gender differences in chronic fatigue syndrome. Reumatol Clin. 2016;12(2):72-7.

24. Harbo HF, Gold R, Tintore M. Sex and gender issues in multiple sclerosis. Ther Adv Neurol Disord. 2013;6(4):237-48.

25. Morris G, Maes M. Myalgic encephalomyelitis/chronic fatigue syndrome and encephalomyelitis disseminata/multiple sclerosis show remarkable levels of similarity in phenomenology and neuroimmune characteristics. BMC Med. 2013;11:205

26. Wang $Y$, Hunt $K$, Nazareth I, Freemantle N, Petersen I. Do men consult less than women? An analysis of routinely collected UK general practice data. BMJ Open. 2013;3(8):e003320.

27. Adamson J, Ben-Shlomo Y, Chaturvedi N, Donovan J. Ethnicity, socioeconomic position and gender-do they affect reported health-care seeking behaviour? Soc Sci Med. 2003;57(5):895-904.

28. Deale A, Wessely S. Patients' perceptions of medical care in chronic fatigue syndrome. Soc Sci Med. 2001;52(12):1859-64.

29. Katafuchi $T$, Kondo T, Take $S$, Yoshimura M. Enhanced expression of brain interferon-alpha and serotonin transporter in immunologically induced fatigue in rats. Eur J Neurosci. 2005;22(11):2817-26.

30. Wuest SC, Mexhitaj I, Chai NR, Romm E, Scheffel J, Xu B, et al. A complex role of herpes viruses in the disease process of multiple sclerosis. PLoS One. 2014;9(8):e105434

31. Katz BZ, Collin SM, Murphy G, Moss-Morris R, Wyller VB, Wensaas K-A, et al. The international collaborative on fatigue following infection (COFFI). Fatigue : Biomed Health Behavior. 2018;6(2):106-21.

32. Chia JK, Chia AY. Chronic fatigue syndrome is associated with chronic enterovirus infection of the stomach. J Clin Pathol. 2008;61(1):43-8.
33. Clark C, Goodwin L, Stansfeld SA, Hotopf M, White PD. Premorbid risk markers for chronic fatigue syndrome in the 1958 British birth cohort. The British J Psychiat. 2011;199(4):323-9.

34. Kato K, Sullivan PF, Evengard B, Pedersen NL. Premorbid predictors of chronic fatigue. Arch Gen Psychiatry. 2006;63(11):1267-72.

35. De Bolle L, Naesens L, De Clercq E. Update on human herpesvirus 6 biology, clinical features, and therapy. Clin Microbiol Rev. 2005;18(1):217-45. https://doi.org/10.1128/CMR.1118.1121.1217-1245.2005.

36. Arzomand ML. Chronic fatigue syndrome among school children and their special educational needs. J Chron Fatigue Synd. 1998;4(3):59-69.

37. Dowset EG, Colby J. Long-term sickness absence due to ME/CFS in UK schools. J Chron Fatigue Synd. 1997;3(2):29-42

38. Naess H, Nyland M, Hausken T, Follestad I, Nyland HI. Chronic fatigue syndrome after giardia enteritis: clinical characteristics, disability and longterm sickness absence. BMC Gastroenterol. 2012;12:13.

39. Kingdon CC, Bowman EW, Curran H, Nacul L, Lacerda EM. Functional Status and Well-Being in People with Myalgic Encephalomyelitis/Chronic Fatigue Syndrome Compared with People with Multiple Sclerosis and Healthy Controls. Pharmacoecon Open. 2018;2(4):381-392. https://doi.org/10.1007/ s41669-018-0071-6.

40. Afari N, Buchwald D. Chronic fatigue syndrome: a review. Am J Psychiatry. 2003:160(2):221-36.

41. Katon WJ, Buchwald DS, Simon GE, Russo JE, Mease PJ. Psychiatric illness in patients with chronic fatigue and those with rheumatoid arthritis. J Gen Intern Med. 1991;6(4):277-85.

42. Mariman A, Delesie L, Tobback E, Hanoulle I, Sermijn E, Vermeir $\mathrm{P}$, et al. Undiagnosed and comorbid disorders in patients with presumed chronic fatique syndrome. J Psychosom Res. 2013;75(5):491-6.

43. Newton JL, Mabillard H, Scott A, Hoad A, Spickett G. The Newcastle NHS chronic fatigue syndrome service: not all fatigue is the same. J R Coll Physicians Edinb. 2010;40(4):304-7.

44. Virtanen JO, Jacobson S. Viruses and multiple sclerosis. CNS Neurol Disord Drug Targets. 2012;11(5):528-44.

45. Norris T, Collin SM, Tilling K, Nuevo R, Stansfeld SA, Sterne JA, et al. Natural course of chronic fatigue syndrome/myalgic encephalomyelitis in adolescents. Arch Dis Child. 2017;102(6):522-8.

46. Jain V, Arunkumar A, Kingdon C, Lacerda E, Nacul L. Prevalence of and risk factors for severe cognitive and sleep symptoms in ME/CFS and MS. BMC Neurol. 2017;17(1):117.

\section{Publisher's Note}

Springer Nature remains neutral with regard to jurisdictional claims in published maps and institutional affiliations.

Ready to submit your research? Choose BMC and benefit from:

- fast, convenient online submission

- thorough peer review by experienced researchers in your field

- rapid publication on acceptance

- support for research data, including large and complex data types

- gold Open Access which fosters wider collaboration and increased citations

- maximum visibility for your research: over $100 \mathrm{M}$ website views per year

At BMC, research is always in progress.

Learn more biomedcentral.com/submission 